\title{
Smart increment borer: a portable device for automated sampling of tree-ring cores
}

\author{
Akira Kagawa $^{1}$ (D) Takeshi Fujiwara ${ }^{1}$
}

Received: 26 June 2017 / Accepted: 16 September 2017/Published online: 6 October 2017

(C) The Japan Wood Research Society 2017

\begin{abstract}
Manual sampling of large number of cores is an arduous task, especially when core diameter is large. We developed an automated tree-ring sampling device, the "smart increment borer", to increase the sample throughput and minimize the need for muscular exertion. The lightweight, portable device employs a battery-powered electric wrench and the complete system to drive the boring operation weighs less than $10 \mathrm{~kg}$. It is capable of taking both 5 - and $12-\mathrm{mm}$ diameter cores of more than $80-\mathrm{cm}$ length. Compared to equipment used in previously published articles, this device enables more rapid sampling and demonstrates a superior torque output/total weight ratio. The device is also capable of facilitating the starting operation of a $12-\mathrm{mm}$ increment borer. It facilitates a variety of effective sampling solutions for dendrochronology/climatology and wood anatomy/quality research.
\end{abstract}

Keywords Tree rings - Gear - Tree breeding - SilviScan . Wood quality

\section{Introduction}

For many researchers in wood and forest sciences, increment borer is a preferred way of sampling because it can take wood core samples without killing the living tree. Manual increment borers have a tapered cutting thread at the tip, which draws the borer into the stem when rotated.

Akira Kagawa

akagawa@ffpri.affrc.go.jp

1 Wood Anatomy and Quality Laboratory, Forestry and Forest Products Research Institute, Tsukuba, Ibaraki 305-8687, Japan
They are the most commonly used tool to obtain core samples, typically from 4.35 to $12 \mathrm{~mm}$ in diameter [1]. The bit for sampling $12 \mathrm{~mm}$ cores has the outer diameter of $19 \mathrm{~mm}$. Owing to high contact surface area and large friction forces with the wood, the increment borer needs a high torque to penetrate the wood, especially when sampling $12 \mathrm{~mm}$ cores.

Generally, the "cutting" by the threads of increment bores produces no sawdust during coring. Apart from a "cutting" increment borer type, there is a "sawing" increment bore type, which utilizes a plug cutter instead of cutting edge at the tip of the bit [2]. The plug cutter produces sawdust (or splints) when coring. One of the main advantages of the sawing increment borer is its reduced friction on the outside of the drill compared to cutting increment borer. The sawing increment borer requires smaller torque for coring, and therefore is suited for sampling long cores of hardwood (e.g., "Dendrobohrer" by Pressler GmbH) [3]. The disadvantage is longer time required for coring.

For measurement of tree age, ring widths, and densitometry, the smaller $5 \mathrm{~mm}$ cores are preferred. For analyses of stable isotopes, radioisotopes such as radiocarbon and ${ }^{137} \mathrm{Cs}$, and inorganic elements, a larger mass of wood is required and large-diameter cores $(12 \mathrm{~mm})$ are preferably used [4]. When density is measured with the water displacement method, large cores are preferred [5] because larger cores can provide density values with higher accuracy [6]. They are also preferred for measuring fiber lengths because $12 \mathrm{~mm}$ is large enough to include entire fibers of conifers and they can be micro-pulped for evaluation of paper quality [5]. For evaluation of wood in tree breeding programs, coring is sometimes preferred to felling because breeders prefer the trees to stay alive for later use. 
Accordingly, there is a widespread interest in mechanical sampling of $12 \mathrm{~mm}$ cores.

Several attempts have been made to mechanize the collection of wood core samples, especially larger diameter cores, using either electrical [2, 7-9], gas [3, 5, 7, 10-12] or hydraulic power tools [13]. These attempts, however, have been met with limited success, mainly because they lack effective means to absorb reaction force without sacrificing portability. The power sources of these devices have been relatively massive $[10,12,13]$ and they use operator's arms $[7,12,13]$ to support the large reaction force generated by the power source. None of the previous devices had a reaction bar designed to be supported by the operator's leg (Table 1), which can support much stronger force than arms. Other devices used a frame fixed to the tree stem and/ or the ground to absorb the large reaction force $[8,10,11]$. This increased the total weight of the machine.

A suitable coring device should be lightweight, have large torque and maintain optimum coring speed. Previous devices could meet one or two of these conditions; however, none could meet all of these conditions in one device. Because of this limitation, previously developed machines did not gain popularity among the researchers, and most continued to rely on manual coring. The technical obstacles for existing coring machines are summarized into the following four important features.

The first important feature is power source. Gasoline engines, such as the one used for a chainsaw [12] or for an engine drill [5, 7], can produce large torque. However, gasoline engines are rather heavy (for example, Tanaka
TED-270RS weighs $6.0 \mathrm{~kg}$ with a full tank) and it is physically challenging to support this weight throughout the entire coring process. A battery-powered wrench is lighter, but lacks sufficient torque for coring with the cutting increment borer. Furthermore, rotational speed of an electric wrench or engine drill $(390-1600 \mathrm{rpm})$ is too fast for the cutting increment borer. These power sources, when used alone, may cause overheating of the cutting edges, resulting in burnt core surface [5].

The second important feature is gear. To convert the high-speed low-torque input into low-speed, high-torque output suitable for the driving of an increment borer, various torque-enhancing gears have been utilized, such as the worm gear [11] and the earth auger gear [5, 7]. Compared to these gears, the planetary gear (Fig. 1) has advantages such as high-torque output/weight ratio, high energy efficiency, and coaxial gear arrangement [14].

The third important feature is the reaction bar. All electric drills, engine drills, and chainsaws used in conventional mechanical boring systems have small reaction bars that are designed to be supported by the operator's hand [5, 7, 9, 12]. For example, a gasoline-powered chainsaw fitted with small reaction bar and the Atom brand drilling attachment was developed to drive an increment borer [12]. With the small reaction bar, it was difficult for an operator to absorb the strong reaction force, and as we discuss later, it was even dangerous. Other previous devices use frames to absorb the reaction force, which are fastened either to the tree stem/ground or onto a carriage $[8,10,11]$. Frames can absorb the reaction force more

Table 1 A performance comparison between the smart increment borer (Smartborer) and previous devices

\begin{tabular}{|c|c|c|c|c|c|c|c|}
\hline References & $\begin{array}{l}\text { Core } \\
\text { diameter } \\
(\mathrm{mm})\end{array}$ & $\begin{array}{l}\text { Total } \\
\text { weight } \\
(\mathrm{kg})\end{array}$ & $\begin{array}{l}\text { Gear } \\
\text { ratio }\end{array}$ & $\begin{array}{l}\text { Max core } \\
\text { length } \\
(\mathrm{cm})\end{array}$ & $\begin{array}{l}\text { Penetration } \\
\text { speed }(\mathrm{cm} / \\
\text { min) }\end{array}$ & $\begin{array}{l}\text { Reaction } \\
\text { support }\end{array}$ & Remarks \\
\hline This study & 5 & $6.0^{\mathrm{a}}$ & $1: 24$ & $\begin{array}{l}\text { More } \\
\text { than } 80\end{array}$ & 50 & $\begin{array}{l}\text { Leg and } \\
\text { arms of the } \\
\text { operator }\end{array}$ & $\begin{array}{l}\text { One battery can sample } 5.5 \text { cores of } 50 \mathrm{~cm} \text { length } \\
\text { (Cedrus deodara) and } 36 \text { cores of } 14 \mathrm{~cm} \text { length } \\
\text { (Larix kaempferi) }\end{array}$ \\
\hline $\begin{array}{l}\text { Hall and } \\
\text { Bloomberg } \\
{[12]}\end{array}$ & & 11 & $\begin{array}{l}1: 10- \\
1: 11\end{array}$ & $\begin{array}{l}\text { More } \\
\text { than } 80\end{array}$ & n.a. & Arms & There is a risk of wrist injury \\
\hline Johansen [7] & & $\begin{array}{l}\text { More } \\
\text { than } \\
18\end{array}$ & $1: 5$ & n.a. & 98 & Arms & Electric drill $(4.5 \mathrm{~A})$ is used \\
\hline This study & 12 & $9.5^{\mathrm{a}}$ & $\begin{array}{l}1: 24- \\
1: 118\end{array}$ & $\begin{array}{l}\text { More } \\
\text { than } 80\end{array}$ & $12-50$ & $\begin{array}{l}\text { Leg and } \\
\text { arms }\end{array}$ & $\begin{array}{l}\text { One battery can sample } 4.0 \text { cores of } 40 \mathrm{~cm} \text { length } \\
\text { (C. deodara) and } 26 \text { cores of } 14 \mathrm{~cm} \text { length }(L . \\
\text { kaempferi) }\end{array}$ \\
\hline $\begin{array}{l}\text { Krottenthaler } \\
\text { et al. [3] }\end{array}$ & & 23 & None & 270 & 1.5 & $\begin{array}{l}\text { Support } \\
\text { frame }\end{array}$ & Sawing increment borer is used \\
\hline $\begin{array}{l}\text { Johansen [7] } \\
\text { and Downes } \\
\text { et al. [5] }\end{array}$ & & $\begin{array}{l}\text { More } \\
\text { than } 6\end{array}$ & $1: 20$ & n.a. & 37.5 & Arms & $\begin{array}{l}\text { Tanaka engine drill is used, but it is "slightly } \\
\text { underpowered" [5] }\end{array}$ \\
\hline
\end{tabular}

${ }^{\mathrm{a}}$ Total weight includes that of electric wrench, gearbox, reaction bar, expandable bar and winch socket (a-d and g in Fig. 2) 


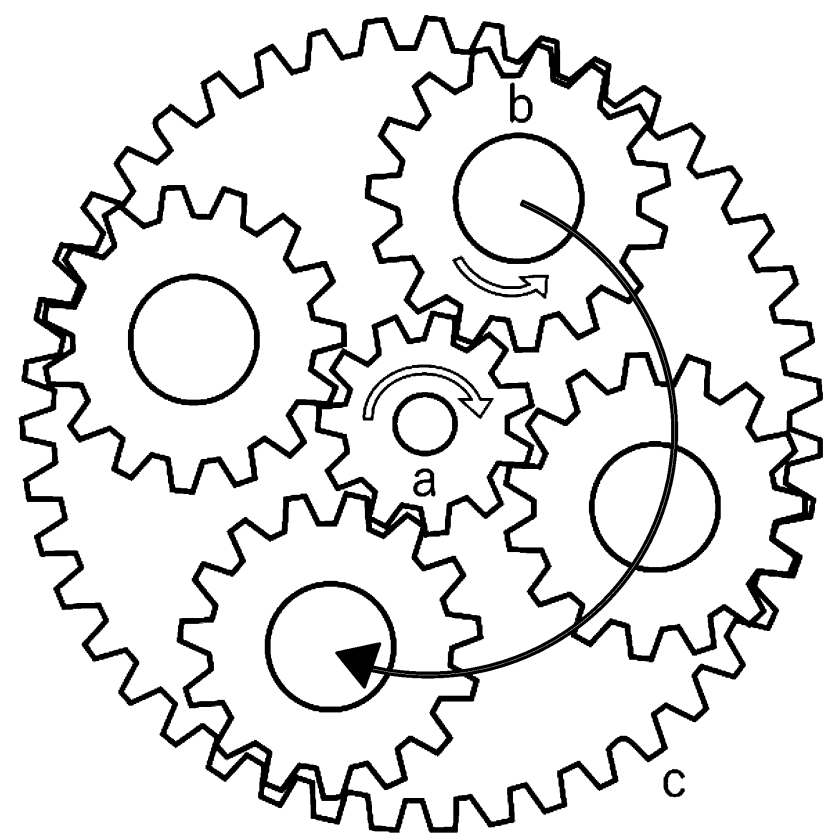

Fig. 1 Planetary gear system used for the gearbox. Planetary gear system consists of a sun gear, $\mathbf{b}$ planet gears, and $\mathbf{c}$ ring gear. When the sun gear rotates clockwise, the planet gears rotate counterclockwise (white arrows). The ring gear is fixed. The four axes of the planetary gears rotate in clockwise direction at a slower angular velocity than the sun gear (black arrow), generating a larger torque. The gear ratio of the depicted gear system is about $1: 5$, which can be calculated from the number of teeth in each gear $((11+43) /$ $11=4.91)$

effectively than arms. However, mounting/unmounting the frames at each coring is time consuming.

In our empirical estimation, the torque required for sampling 12-mm-thick 80-cm-long cores from Japanese oak (Quercus crispula) or teak (Tectona grandis) exceeds $500 \mathrm{~N} \mathrm{~m}$. For absorbing such a large reaction force, a longer reaction bar may be more appropriate because (in addition to increased leverage) the operator can support the large reaction force more easily with his or her leg instead of arms.

The fourth important feature is the facility of starting and extracting an increment borer. Previous devices lack the means to start a borer bit or to extract a borer bit when it becomes lodged in the stem. The former situation arises especially when a physically small person is starting a $12 \mathrm{~mm}$ borer. The latter situation arises, for example, when the bit encounters a hollow pocket or decay in the stem wherein the threads of the bit are unable to engage. Since the $12 \mathrm{~mm}$ bits used to bore trees cost $\$ 1000-2000$, there is an economic incentive to extract these bits when they become lodged.

The objective of this study was to design a mechanical core sampling system that can meet all of the following criteria, and to validate its performance in the field.
The targeted coring system specifications are:

1. Battery operated with a weight less than $10 \mathrm{~kg}$ for facility in fieldwork.

2. Capable of generating sufficient torque $(980 \mathrm{~N} \mathrm{~m})$ to sample long- (up to $80 \mathrm{~cm}$ ) and large-diameter (up to $12 \mathrm{~mm}$ ) cores from the hardest hardwood species. It should be also capable of absorbing the same magnitude of reaction torque $(980 \mathrm{~N} \mathrm{~m})$ with a long reaction bar that can be supported with an operator's leg and/or the ground.

3. Operable by one person and able to achieve efficiency of more than three times greater sample throughput compared to manual coring, when coring every tree at a given site, including various sizes and ages.

4. Capable of instantly initiating a coring operation, without mounting and dismounting a framework to the sample tree or to the ground.

5. Rotation speed should be sufficiently slow (14-67 rpm) to prevent charring of the core surfaces.

6. Rotation direction should be instantly reversible so that the device can quickly extract the borer bit from the tree.

7. Changing of gear ratios should be swift.

8. Capable of starting and extracting a borer bit of up to $12 \mathrm{~mm}$ diameter.

\section{Materials and methods}

\section{Components}

Our automated tree-ring sampling device, which we call the "smart increment borer", or "Smartborer", consists of five major components: power wrench, gearbox, reaction bar, socket and increment borer (Fig. 2). We designed two models, for sampling 5 and $12 \mathrm{~mm}$ cores.

In a typical configuration, an electronic wrench (Fig. 2a) drives the input of the gearbox (Fig. 2b) at $1600 \mathrm{rpm}$, generating output ranging $14-330 \mathrm{rpm}$ on the other side. The gearbox uses small and large gears (Fig. 2b at bottom left), with gear ratio of ca. 1:5 and 1:24, respectively. The small gear contains one set of planetary gear with the ratio of 4.91, and the large gear contains two sets of planetary gear, with the ratio of $24.1\left(=4.91^{2}\right.$, Fig. 1$)$. The gearbox contains either one large gear, or combination of the large and the small gears connected coaxially, to shift the gear ratio from $1: 5$ to $1: 118\left(=4.91^{3}\right)$. Usually, we use gear ratio from $1: 24$ to $1: 118$ and the gearshift takes about $10 \mathrm{~s}$. A reaction bar (Fig. 2c) is necessary to prevent the gearbox from rotating when driving an increment borer. An expandable bar (Fig. 2d) is connected to the lower side of the reaction bar so that the reaction force can be absorbed with a leg of the 


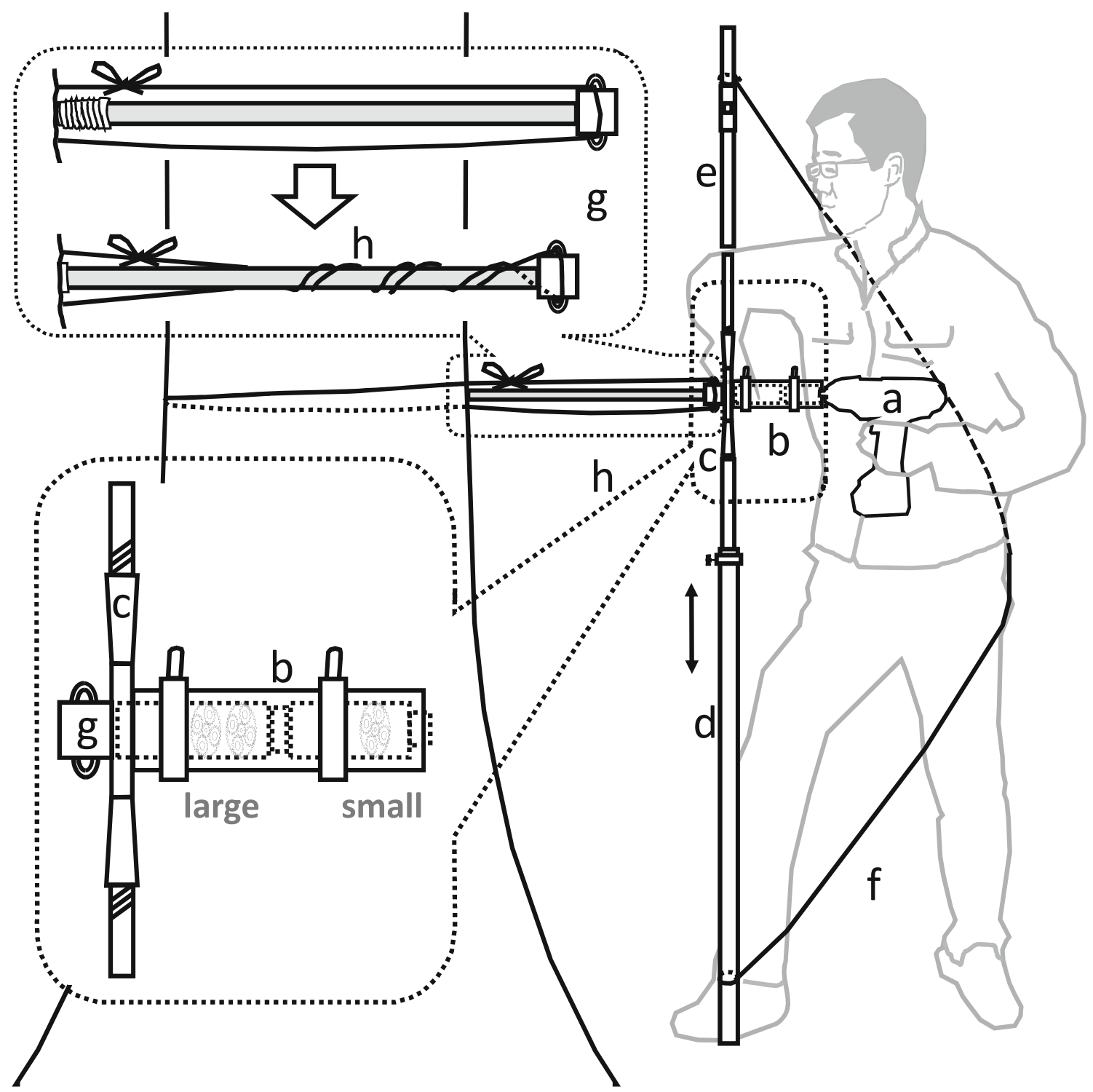

Fig. 2 General view of the smart increment borer. a Power wrench, b gear box, c reaction bar, $\mathbf{d}$ expandable bar, e handle of increment borer, $\mathbf{f}$ rope to support reaction force, $\mathbf{g}$ winch socket, and $\mathbf{h}$ increment borer. The depicted configuration is for the sampling

operator and/or the ground. Alternatively, the handle of an increment borer (Fig. 2e, 5 or $12 \mathrm{~mm}$ handles of Haglof) can be connected to either end of the reaction bar. When coring 12-mm-thick 80-cm-long cores from hardwood, we tied a rope (Fig. 2f) to upper and lower part of the reaction bar/expandable bar. By doing this, the operator could support both sides of the reaction bar to absorb larger reaction force.

There is a socket (Fig. $2 \mathrm{~g}$ ) that connects the output of the gearbox and the square end of an increment borer bit (Fig. 2h). This socket has two eyelets that can be used to thread a rope $(\varphi 5-6 \mathrm{~mm})$. All custom-made parts (Fig. 2b$\mathrm{d}, \mathrm{g})$ are made of stainless steel. of $12 \mathrm{~mm}$ cores. Winch socket can start an increment borer by pressing the cutting edge of increment borer against the stem surface (top left). The gearbox can contain large and small planetary gears, and is able to shift the gear ratio from 1:5 to 1:118 (bottom left)

\section{Operation}

We normally start increment borer by pushing the electric wrench and the reaction bar to insert the threaded part (the first $3 \mathrm{~cm}$ of the tip). When two persons are available, we tilt the reaction bar in horizontal direction, so that each person can push the left or the right side of the reaction bar. By pressing the cutting edge of the bit against the stem with stronger pressure, we can start the $12 \mathrm{~mm}$ borer more easily. However, roughness and thickness of the stem bark often make it difficult to get the borer bit to start engaging, especially when a small and/or inexperienced person tries to start a $12 \mathrm{~mm}$ borer on hardwood alone. To solve this 
problem, we designed a motor-driven socket that can also serve as a winching machine (Fig. $2 \mathrm{~g}$, winch socket). A rope is wrapped around the circumference of the tree trunk, and then put through the eyelets of the winch socket (Fig. 2 top left). After pulling both ends tight, we tie a bow knot to make a loop. Once the winch socket starts driving, the rope winds around the bit until taut and presses the cutting edge of the bit against the stem surface, forcing the bit into the stem (Fig. 2h, top left). After the threaded part goes inside the stem and fully engages with wood, the rope is untied and removed to continue coring.

If the purpose of increment core sampling is to determine exact tree age, a sampled core should include the pith. For precise alignment of the coring direction, one can initially start an increment borer manually with a borer starter until the coring direction is stabilized, then switch to mechanical boring.

After reaching the desired coring depth, we disconnect the socket (Fig. 2g) from the square end of the bit and attach the handle of the increment borer. After manually retrieving the sample core, we connect the smart increment borer (Smartborer) again to the bit end. By simply reversing the rotation setting of the electric wrench, we can rotate the bit counterclockwise and extract the bit out from the stem. We needed lower torque at bit extraction than insertion.

We tested the Smartborer on large $(\mathrm{DBH}>60 \mathrm{~cm})$ Himalayan cedar (Cedrus deodara) and Japanese oak (Quercus crispula) to simulate dendrochronological sampling, and on small (DBH $<30 \mathrm{~cm}$ ) Japanese larch (Larix kaempferi) and Japanese cedar (Cryptomeria japonica) to simulate sampling for wood quality research. We sampled over 200 each of 5 and $12 \mathrm{~mm}$ cores, to mid-diameter, by Smartborer. We used Haglof increment borer bits of 5 and $12 \mathrm{~mm}$ with lengths of $45-80 \mathrm{~cm}$.

\section{Results}

\section{Specifications}

Among the various kinds of power wrenches we have evaluated (battery, gasoline, A.C. outlet and air-compressed), we determined that a heavy-duty electric wrench (Makita TW450D) was the most useful. Despite its portability $(3.5 \mathrm{~kg}$ including a 6.0 Ah-0.7 kg battery Makita BL1860B), it can deliver large torque. Therefore, we decided to use this electric wrench throughout our performance tests.

We sampled all $5 \mathrm{~mm}$ cores at the gear ratio of 1:24. For $12 \mathrm{~mm}$ cores, we started the bit at the gear ratio of 1:24 and continued until the bit became stuck in the wood, which usually happened at the depth of about $22 \mathrm{~cm}$ at conifer sampling. Then we shifted the gear ratio down to $1: 118$ and continued coring to the pith. The torque generated at this gear ratio was sufficient even when taking 12-mm-thick 80 -cm-long cores from large $Q$. crispula. We could save significant amount of battery power by this gearshift because one battery could sample 7.0 and $4.7 \mathrm{C}$. deodara cores of $33-\mathrm{cm}$ length with and without the gearshift, respectively.

The $5 \mathrm{~mm}$ borer requires smaller torque for coring. Due to its smaller reaction force, we used thinner reaction bar of smaller diameter and a lighter square drive socket, reducing the total weight to $6.0 \mathrm{~kg}$ (Table 1). Due to the larger torque required for sampling $12 \mathrm{~mm}$ cores, we had to increase the total weight of the device for sampling $12 \mathrm{~mm}$ cores to $9.5 \mathrm{~kg}$. The rotation speed of the bit stayed almost constant irrespective of penetration depth and the wood species sampled. Using the gear ratios of 1:24 and 1:118, the penetration speeds of the 5 and $12 \mathrm{~mm}$ bits were approximately $50 \mathrm{~cm}$ and $12 \mathrm{~cm}$ per min, respectively (Table 1).

\section{Performance testing in the field}

Although the maximum attainable coring depth is $80 \mathrm{~cm}$, we recommend stopping at shorter coring depth, especially when sampling hardwood. By always keeping 8-12 cm of the bit end outside the stem, the operator can extract a stuck bit by attaching the Decorum extractor [15] to this part.

In the simulated dendrochronological sampling of $C$. deodara, a $6.0 \mathrm{Ah}-0.7 \mathrm{~kg}$ battery produced 5.5 cores $(\varphi 5 \mathrm{~mm})$ of ca. $50 \mathrm{~cm}$ length or 4.0 cores $(\varphi 12 \mathrm{~mm})$ of ca. $40 \mathrm{~cm}$ length (Table 1). In the simulated sampling of $L$. kaempferi for wood quality research, one battery produced 36 cores $(5 \mathrm{~mm})$ of ca. $14 \mathrm{~cm}$ length and 26 cores $(\varphi 12 \mathrm{~mm})$ of ca. $14 \mathrm{~cm}$ length.

Heat generated by friction between outer surface of the borer bit and the surrounding wood did not cause charring of the cores, which was observed with a previous motorized device [5]. Furthermore, we did not observe any other noticeable difference between the mechanical and manual boring, in terms of the frequency in borer damage (nicked blades or broken shaft of the bit), probably because the reduced rotation speed (14-67 rpm) of our device does not differ greatly from that of manual sampling.

We tested the winch socket on the $C$. deodara and $Q$. crispula trees, which could successfully start $12 \mathrm{~mm}$ borer bit. We did not need to use the winch socket for the starting of $5 \mathrm{~mm}$ bit. Climbing rope of 5-6 $\mathrm{mm}$ diameter was the most suitable for the winch socket (Fig. $2 \mathrm{~g}$ ) as well as for supporting the reaction bar (Fig. 2f).

When the bit became stuck by passing into a rotten wood part in the tree stem, the Decorum extractor worked effectively in combination with Smartborer. We attached the extractor and tied a looped rope to the baseplate of the extractor, then simply reversed the borer. The extractor 
converts rotational force from Smartborer to an axial force through a screw mechanism. If the threads of the borer bit grip solidly into healthy, unrotten wood, then the bit starts moving backward through its own rotation, and base plate of the extractor lifts away from the bark naturally. To supplement the axial force generated by the extractor, the operator may lean back slightly, to pull the taut, looped rope backward while reversing. This action can facilitate the withdrawal of the borer bit from healthy wood, as well as from rotten wood.

\section{Discussion}

\section{Comparison with conventional devices}

The biggest advantage of Smartborer is manifested in its reaction bar design. No other device developed so far has the reaction bar designed to absorb reaction force with the operator's leg and/or the ground (Fig. 2). For example, if we assume core sampling at the breast height $(1.3 \mathrm{~m})$ with the maximum allowable torque for the device $(980 \mathrm{~N} \mathrm{~m})$, the leg of the operator has to support $754 \mathrm{~N}(77 \mathrm{~kg})$ of force at the lower end of the expandable bar (Fig. 2d). Mechanical increment boring inevitably generates reaction torque equaling to the large driving torque. Trying to support such a strong reaction force by arm can lead to injury of the operator's arm or wrist, as previously documented (ITRDB Dendrochronology Forum posting on 04/21/2014 by M. Devall) [12]. Alternatively, such a big reaction force can be absorbed by mounting the power unit on a frame fixed to the tree/ground $[10,11]$, however, such a frame increases the weight of the system and the assembly/disassembly of the frame takes time.

The second advantage is the Smartborer's high-torque output/total weight ratio. Our device can be carried by hand or back-packed to more inaccessible woodland areas. A fieldwork campaign for dendrochronological sampling can last up to a few weeks and may require walking long distances over a period of days to reach the study area. Under such circumstances, the weight of the device becomes a crucial issue. Previous devices used for sampling $12 \mathrm{~mm}$ cores are much heavier or otherwise underpowered (Table 1) [5, 8, 10, 11, 13]. In contrast, our device has the highest torque output/total weight ratio.

The third advantage is high sample throughput. Recently developed coring devices have become lighter (e.g., combined weight of $23 \mathrm{~kg}$ for engine, borers and support frame) [3] and are capable of sampling $12 \mathrm{~mm}$ cores from tropical hardwood. However, such devices employ a sawing increment borer [3, 16], which is time consuming. When the sawing increment borer is driven by an enginepowered drill, it takes about $20 \mathrm{~min}$ to sample $30 \mathrm{~cm}$ core
[3]. A cutting increment borer coupled with Smartborer requires only about $3 \mathrm{~min}$ to sample a similar core (Table 1).

However, cutting increment borer does have some disadvantages. High-density hardwood trees with large diameters sometimes damage manually operated cutting increment borers. In our experience, it happens when coring temperate hardwood trees such as $Q$. crispula or tropical hardwood such as $T$. grandis. When coring these species, the cutting edge of the increment borer is sometimes nicked, and in rare cases, the shaft of borer bit can snap. If these problems happen frequently, the "sawing" type increment borer may be a better option. With increasing length and/or diameter of the core, the sampling operation requires greater power to drive the cutting increment borer because the higher surface areas in contact with the wood increase the driving torque.

\section{Recommended device configuration}

Optimum device configuration may differ between, e.g., a xylological sampling trip to plantation forest, which is easily accessible by cars, and a dendrochronological sampling trip to a natural forest that is accessible only by longdistance walk. For the former type of sampling, we normally bring less than four batteries in the backpack for the $12 \mathrm{~mm}$ model and less than three batteries for the $5 \mathrm{~mm}$ model. The batteries typically may be recharged every day at the accommodation after use. For the latter type of sampling, we bring either (1) as many batteries as we can carry, or (2) four batteries, two rechargers, and an inverter generator (Yamaha EF900iS, dry weight $12.7 \mathrm{~kg}$ ). By connecting two rechargers to one generator, we can recharge two batteries every hour.

\section{Conclusions}

Our device is a significant improvement over other portable devices reported in the literature (Table 1) because it achieves two seemingly incompatible targets simultaneously; lighter weight and higher torque output. The device is especially effective when sampling a large number of cores and/or large-diameter cores at forests that are easily accessible by car. When sampling cores for wood quality research, we were able to increase the sample throughput by more than three times compared to the manual procedures, and also eliminate severe muscular exertion by the operator. Our device also enables researchers, especially smaller persons and females, to obtain long- and large-diameter cores that typically were not feasible by manual coring. The basic configuration of our device consists of the large gear, reaction bar and 
socket. Based on common prices in 2017, devices capable of sampling $5 \mathrm{~mm}$ and $12 \mathrm{~mm}$ cores may cost about 700,000 and 800,000 Japanese yen, respectively.

Acknowledgements The authors would like to thank Kana Yamashita and Shinta Ohashi for their help in field-testing and for their feedback to improve the device. We would also like to thank Brian Landberg for reviewing early drafts of this paper. This work was supported by JSPS KAKENHI Grant number 25292111. For further information about the smart increment borer, please email the corresponding author or search for "Smartborer" on the internet.

\section{References}

1. Grissino-Mayer HD (2003) A manual and tutorial for the proper use of an increment borer. Tree-Ring Res 59(2):63-79

2. Prestemon DR (1965) Improving the power increment borer for hardwoods. J For 63(10):763-765

3. Krottenthaler S, Pitsch P, Helle G, Locosselli GM, Ceccantini G, Altman J, Svoboda M, Dolezal J, Schleser G, Anhuf D (2015) A power-driven increment borer for sampling high-density tropical wood. Dendrochronologia 36:40-44

4. Kagawa A, Sano M, Nakatsuka T, Ikeda T, Kubo S (2015) An optimized method for stable isotope analysis of tree rings by extracting cellulose directly from cross-sectional laths. Chem Geol 393-394(30):16-25

5. Downes GM, Hudson IL, Raymond CA, Dean GH, Michell AJ, Schimleck LR, Evans R, Muneri A (1997) Sampling plantation eucalypts for wood and fibre properties. CSIRO Publishing, Collingwood

6. Chave J, Muller-Landau HC, Baker TR, Easdale TA, ter Steege $\mathrm{H}$, Webb CO (2006) Regional and phylogenetic variation of wood density across 2456 neotropical tree species. Ecol Appl 16(6):2356-2367

7. Johansen RW (1987) Taking increment cores with power tools. South J Appl For 11(3):151-153

8. Steenkamp CJ, van Rooyen MW, van Rooyen N (1999) A nondestructive sampling method for dendrochronology in hardwood species. South Afr For J 186(1):5-7

9. Speer JH (2010) Archaeological methods. In: Speer J (ed) Fundamentals of tree-ring research. University of Arizona Press, Tucson, pp 154-161

10. Bowers NA (1960) Research completed on power-driven tools for taking long core-borings. Tree-Ring Bull 23(1):10-13

11. Yelf JT (1962) The development of a power increment borer. For Chron 38(3):309-317

12. Hall AA, Bloomberg WJ (1984) A power-driven increment borer. For Chron 60(6):356-357

13. Echols RM (1969) Powered drive for large increment borers. J For 67(2):123-125

14. Ambarisha VK, Parker RG (2007) Nonlinear dynamics of planetary gears using analytical and finite element models. J Sound Vib 302(3):577-595

15. Loader NJ, Waterhouse JS (2014) An extractor device for stuck or broken increment bores. Tree-Ring Res 70(2):157-160

16. Williams RE, Gagen MH, Walsh RPD, Bidin K (2015) On the development of a drill-borer for sampling tropical supra-hardwoods: an example using the Borneo ironwood Eusideroxylon zwageri. Dendrochronologia 35:99-104 